удк 343.8

DOI 10.24147/2542-1514.2020.4(3).148-157

(cC) BY 4.0

\begin{abstract}
НЕПРАВОМЕРНОЕ ПРИМЕНЕНИЕ В ОТНОШЕНИИ ЛИЦ, ЛИШЕННЫХ СВОБОДЫ, ФИЗИЧЕСКОЙ СИЛЫ И СПЕЦИАЛЬНЫХ СРЕДСТВ: КРИМИНОЛОГИЧЕСКАЯ ХАРАКТЕРИСТИКА И МЕРЫ ПРОФИЛАКТИКИ
\end{abstract}

\author{
А.М. Смирнов \\ Научно-исследовательский институт ФСИН России, г. Москва, Россия
}

\begin{abstract}
Изложена криминологическая характеристика неправомерного применения в отношении лиц, лишенных свободы, физической силы и специальных средств, включающая характеристику личности осужденных к лишению свободы, в отношении которых было совершено подобное неправомерное применение, обстоятельств его осуществления, основные причины, этому способствующие, а также характеристика личности сотрудников исправительных учреждений, допускавших подобное применение. Делаются выводы, что неправомерное применение физической силы и специальных средств было осуществлено в отношении осужденных с достаточно негативными характеристиками, отличающимися высокой степенью криминальной зараженности, проявляющими отрицательное отношение к порядку и условиям отбывания наказания, не подчиняющимися законным требованиям сотрудников исправительных учреждений. Наиболее вероятные причины подобного применения связаны с особенностями проявления противоправной активности таких осужденных, негативными характеристиками условий отбывания наказания и особенностями несения службы, деструктивно влияющими на сотрудников данных учреждений. Всё это необходимо учитывать при проведении профилактики рассматриваемого негативного явления в отечественной пенитенциарной практике, оптимальные направления реализации которой изложены в заключение работы.
\end{abstract}

\title{
ILLEGAL USE OF PHYSICAL FORCE AND SPECIAL MEANS AGAINST PRISONERS: CRIMINOLOGICAL CHARACTERISTICS AND PREVENTIVE MEASURES
}

\section{Alexander M. Smirnov}

Research Institute of the Federal Penitentiary Service of Russia, Moscow, Russia

Article info
Received -
2020 July 03
Accepted -
2020 August 20
Available online -
2020 October 01
Keywords
Penitentiary crime, prevention of
penitentiary crime, physical force,
special means, prisoner,
imprisonment, penal system,
correctional institution, use of
special means

Article info

August 20

Available online -

Keywords

Penitentiary crime, prevention of penitentiary crime, physical force, special means
The subject. The article outlines the criminological characteristics of the ilegal use of physical force and special means against persons deprived of their liberty.

The purpose of the article is confirmation or confutation of the hypothesis that the reasons for the unlawful use of force methods against convicts are related to the nature of the illegal actions of such convicts.

The methodological base of the study was an analysis of 15 cases of unlawful use of physical force and special means by employees of the correctional facilities against imprisoned convicts committed in the period from 2016 to 2019. The author analyzed 12 sentences on bringing employees of the correctional facilities to criminal responsibility for the unlawful use of these forceful methods, as well as a survey of about 190 employees serving in various positions in the correctional facilities where unlawful use of force was carried out. In addition the scientific works of other authors that affect this issue were studied.

The main results, scope of application. The criminological characteristics of the illegal use of physical force and special means by employees of the correctional facilities against imprisoned persons are presented. The article includes a description of such victims; a description of the circumstances of use of force; a description of the employees of the correctional 
facilities who allowed unlawful use of force; the reasons and conditions that contribute to the implementation of this use. Based on the above, some measures are proposed that contribute to the optimal solution of the issue of prevention of the unlawful use of force in the Russian penitentiary practice.

Conclusions. The unlawful use of physical forces and special means was carried out against convicts who have destructive moral and psychological qualities, are characterized by a high degree of criminal infection, express a negative attitude towards order and conditions of serving sentences and do not obey the legal requirements of correctional staff. A generalization of the personal characteristics of employees who unlawfully use physical force and (or) special means indicating that they are characterized by positive psychological qualities in general. They strive to be guided by the regulations governing the professional activities of the penal system officer and are positively active in fulfilling their duties. The most probable reasons for the unlawful use of forceful methods of influence against convicts are related to the nature of the unlawful actions of such convicts, provocations, negative features of service due to the specifics of places of deprivation of liberty. Measures taken to prevent the occurrence of negative phenomena in domestic politics can have a positive impact on improving the functioning of the penal correction system, which is in line with legal regulations of a national and international nature.

1. Введение. Актуализация проблемы исследования.

Как известно к лишению свободы приговариваются лица, совершившие наиболее общественно опасные преступные деяния, принесшие существенный вред правам и свободам человека и гражданина, обществу и государству, иным социальным благам и ценностям. Эти лица заслуживают наиболее строгого государственного реагирования, содержащего в себе элементы адекватной кары, согласующейся с характером совершенных ими деяний и наступивших от них последствий [1]. Именно поэтому российское уголовное законодательство справедливо придерживается принципа соразмерности наказания с характером и степенью общественной опасности совершенного преступного деяния (ч. 1 ст. 6 Уголовного кодекса Российской Федерации (УК РФ)). Однако, с другой стороны, в нем закреплен принцип гуманного отношения к преступникам (ст. 7 УК РФ), ставший итогом многолетней борьбы различного рода гуманистов за права и свободы лиц, причиняющих законопослушным гражданам различного рода страдания, зачастую невосполнимые и «калечащие» их жизни.

Как следствие, российская уголовно-исполнительная система (УИС) придерживается принципов гуманного, законного, уважительного отношения к наиболее опасным преступникам, осужденным к наиболее строгому виду уголовного наказания - лишению свободы. Необходимо отметить, что спектр проявлений гуманизма к таким преступникам на практике постоянно расширяется, что проявляется в решении вопросов улучшения порядка и условий от- бывания наказания, обеспечения все большей защиты их прав и свобод. Все это происходит благодаря активному участию международных и отечественных правозащитных организаций.

В настоящее время одним из главных векторов развития российской уголовной политики является назначение наказания в виде лишения свободы только в крайних случаях, за совершение наиболее опасных преступных деяний. При этом назначение такого наказания должно быть подробно аргументировано судом в своем приговоре, что иной вид государственного принуждения не применим к осужденному для эффективного достижения целей уголовного наказания. То, что в данном направлении суды работают достаточно исполнительно, указывает то обстоятельство, что согласно анализу данных Судебного департамента при Верховном суде Российской Федерации за последние пять лет назначение наказания в виде отбытия реального лишения свободы сократилось на 17 \% (с 211170 осуждений в 2015 г. до 175122 - в 2019 г.). Сокращение числа таких осуждений напрямую связано с сокращением числа всех осужденных в рассматриваемый промежуток времени ан 18,5 \% (с 733607 осужденных в 2015 г. до 598214 - в 2019 г.). Тем не менее доля осуждений к отбытию реального лишения свободы среди назначения иных мер государственного принуждения остается практически неизменной - не более $30 \%$ (в 2015 г. она составила 28,8 \%, в 2019 г. - 29,3 \%).

В связи с вышеизложенным, не удивительно, что в местах лишения свободы концентрируется самая криминально опасная часть преступников, испытывающих наиболее негативное отношение к обще- 
ству и государству, ведущая криминальный образ жизни [2]. Именно поэтому, как показывает практика, значительной части из таких преступников бывает крайне сложно соблюдать условия отбывания наказания, выполнять законные требования сотрудников администрации исправительных учреждений (ИУ) [3; 4]. Так, например, согласно анализу статистических данных Федеральной службы исполнения наказаний (ФСИН России) в рассматриваемый промежуток времени увеличилось число совершаемых осужденными к лишению свободы, отбывающих наказание в ИУ для взрослых, нарушений установленного порядка отбывания наказания (УПОН) в расчете на 1000 человек - с порядка 1100 случаев в 2015 г. до около 1400 случаев в 2019 г. Для злостных нарушений УПОН в данный промежуток времени это показатель практически не изменился и удерживался на уровне порядка 40 нарушений.

Безусловно, такую высокую правонарушающую активность осужденных к лишению свободы надо как-то сдерживать и делать это достаточно эффективно, поскольку от этого напрямую зависит безопасность персонала ИУ, лиц, посещающих данные учреждения, а также иных осужденных, находящихся в них. Одним из результативных средств для этого является применение физической силы и специальных средств. Это применение выступает крайней мерой, итогом реализации которой, исходя из сложившейся обстановки может стать причинение вреда жизни и здоровью осужденным [5]. В связи с чем, реализация данной меры строго регламентирована.

Именно поэтому ФСИН России уделяет особое внимание вопросам недопущения неправомерного применения в отношении осужденных к лишению свободы физической силы и специальных средств, для чего постоянно разрабатывает меры по профилактики этого негативного явления в отечественной пенитенциарной практике, обращаясь при этом к помощи научного сообщества. Вместе с тем, не смотря на эти меры, продолжают происходить случаи подобного неправомерного применения, поскольку сотрудники ИУ, ответственные за поддержание законности и правопорядка, порой не всегда могут сдерживать свои эмоции и полностью руководить своими действиями, понимая с какой категорией лиц им приходиться работать, при этом находясь в негативных, стрессовых условиях мест лишения свободы.

Анализ статистических данных ФСИН России свидетельствует о том, что работа данного ведомства в направлении профилактики рассматриваемого неправомерного применения показывает пока еще недоста- точно удовлетворительные результаты, поскольку в указанный выше промежуток времени число привлечений сотрудников ИУ к ответственности за данное применение увеличилось практически в 15 раз.

Изложенное свидетельствует об актуальности и своевременности проведения криминологических исследований, целью которых выступает изучение неправомерного применения сотрудниками ИУ физической силы и специальных средств в отношении преступников, отбывающих наказания в местах лишения свободы, с последующей выработкой научнообоснованных предложений и рекомендаций по профилактике данного негативного явления в отечественной пенитенциарной практике.

Определенным вкладом в эту работу выступает настоящая научная статья, в которой представлена криминологическая характеристика неправомерного применения сотрудниками ИУ физической силы и специальных средств в отношении осужденных к лишению свободы, включающая в себя характеристику таких осужденных, в отношении которых было совершено данное применение; характеристику обстоятельств совершения данного применения; характеристику сотрудников ИУ, допустивших подобное применение; причины и условия, способствующие осуществлению данного применения. На основании изложенного предложены некоторые меры, способствующие оптимальному решению вопроса профилактики рассматриваемого негативного явления в российской пенитенциарной практике.

\section{2. Эмпирическая база исследования}

Эмпирическую базу исследования составил анализ 15 случаев неправомерного применения сотрудниками ИУ физической силы и специальных средств в отношении осужденных, отбывающих наказание в виде лишения свободы, совершенных данными сотрудниками в период с 2016 по 2019 годы, 12 приговоров о привлечении сотрудников ИУ к уголовной ответственности за неправомерное применение данных силовых методов воздействия, а также анкетирование около 190 сотрудников, проходящих службу на различных должностях в ИУ, в которых были осуществлены исследуемые применения. Помимо этого при написании работы были изучены научные труды иных авторов, затрагивающие данную проблематику.

3. Характеристика осужденных, в отношении которых были неправомерно применены физическая сила и специальные средства

Наше исследование показало, что такими осужденными были лица мужского пола, находящиеся в 
зрелом возрасте (более подробное распределение по возрастным категориям показало, что максимальное число (30 \%) таких осужденных находилось в возрасте от 31 года до 35 лет, далее следуют лица в возрасте от 26 до 30 лет, от 36 до 40 лет и от 41 года до 45 лет в равных пропорциональных долях (по $20 \%)$ и меньше всего жертвами рассматриваемого применения были осужденные в возрасте от 19 до 25 лет (10\%)).

Исследование образовательного уровня данных осужденных позволило сделать вывод, что он достаточно невысокий, поскольку до осуждения практически каждый второй из них имел образование не выше среднего профессионального. При этом практически каждый пятый из них сумел получить только неоконченное среднее образование. Остальные осужденные до совершения преступного деяния имели только полное среднее образование.

Осужденные, ставшие жертвами неправомерного применения силовых методов воздействия, были приговорены к лишению свободы в основном за совершение корыстных и насильственных преступных деяний, объектом посягательства которых чаще всего выступили собственность (27,3 \%), установленный в стране оборот оружия и боеприпасов (27,3 \%), нормативные правила оборота психотропных веществ и наркотиков (18,2 \%), здоровье граждан (18,2 \%) и их жизнь (9 \%).

Обобщение полученных данных показало, что частично признало свою вину в совершенном преступлении только половина осужденных исследуемой группы; каждый десятый абсолютно не признал свою виновность в преступном деянии, за которое отбывал наказание, что демонстрирует их достаточно низкую степень ответственности за совершенные вредоносные деяния.

Данные осужденные отличаются высокой степенью криминальной зараженности и им свойственно ведение антисоциального образа жизни, поскольку большая часть из них (80 \%) находятся в местах лишения свободы более двух раз. При этом $40 \%$ из них осуждены к длительным срокам заключения (более 5 лет).

Подавляющему большинству осужденных исследуемой группы (90\%) было определено судом отбывание лишения свободы в исправительной колонии (ИК) строгого режима. При этом четверо из пяти таких осужденных были направлены в данные учреждения, предназначенные для лиц, ранее отбывавших лишение свободы.
Большинство осужденных исследуемой группы во время отбывания наказания не стремились улучшить условия своего нахождения в ИУ посредством исправления, демонстрируя тем самым негативное или равнодушное отношение к условиям и установленному порядку отбывания наказания (УПОН), о чем свидетельствует то обстоятельство, что $60 \%$ из них на время проведения исследования находились на обычных условиях и 40 \% - на строгих условиях отбывания наказания. Помимом этого около 60 \% данных осужденных за наличие объективных подозрений совершать противоправные поступки были поставлены на профилактический учет. Большую часть осужденных, поставленных на данный учет, составили лица склонные к систематическому несоблюдению установленных в ИУ правил внутреннего распорядка (30 \%), аутоагрессивному поведению, выражающемуся в членовредительстве и суициде (20\%), нападению на персонал ИУ и сотрудников иных правоохранительных органов (20\%), употреблению наркотиков, психотропных средств, медицинских препаратов, обладающих сильным воздействием на организм человека, и алкогольсодержащих напитков (10\%), а также совершению побега (10\%).

Осужденные исследуемой группы в дисциплинарном отношении характеризовались весьма негативно, поскольку все они нарушали УПОН. При этом большая часть из них (60\%) злостно нарушали данный порядок, а подавляющее большинство (90 \%) их них нарушали его подобным образом систематически.

Об отрицательном отношении данных осужденных порядку отбывания наказания указывает то обстоятельство, что большинство из них (80\%), находясь в ИУ, не проявляли желание выполнять свои трудовые обязанности, изыскивая для этого различные уважительные причины. Помимо этого такая же доля осужденных рассматриваемой группы не старались повышать свой уровень знаний, считая, что им достаточно того образования, которое они получили до осуждения [6, с. 34]. Каждый третий такой осужденный не стремился поддерживать социально полезные связи, причем у каждого десятого такие связи вообще отсутствовали [7, с. 24].

Отмечено достаточно благоприятное отношение осужденных данной группы к обычаям и традициям тюремной субкультуры, что вполне очевидно. Так 20 \% из них демонстрировали положительное к ним отношение и старались во всем соблюдать, а 30 \% помимо этого провялили инициативу по активной пропаганде данных обычаев и традиций среди иных лиц, лишенных свободы. 
Выявлено у данных осужденных преобладание негативных психологических характеристик над позитивными. Среди них доминируют агрессивность, конфликтность, грубость, импульсивность, неустойчивая самооценка, повышенная эмоциональность, озлобленность, обидчивость, раздражительность, циничность, мстительность, эгоцентризм, отсутствие целей в жизни, пессимизм, скудность познавательной сферы деятельности, депрессивность, негативное отношение к установленным нормам и правилам поведения, бравирование преступным образом жизни, отсутствие способности адекватно оценивать возникающие конфликтные ситуации, совершать правильные поступки для их разрешения. Именно поэтому по свидетельству пенитенциарных психологов для исправления большей части (80 \%) осужденных исследуемой группы необходимо применение не только методов убеждения, но и содержащих элементы воздействия (принуждения).

4. Характеристика обстоятельств неправомерного применения в отношении осужденных к лишению свободы физической силы и специальных средств

Анализ обстоятельств неправомерного применения рассматриваемых силовых методов воздействия в отношении осужденных к лишению свободы указывает на то, что подобные случаи происходили в основном ИК строгого вида режима (80 \%) для мужчин, повторно осужденных к реальному отбытию лишения свободы (80 \%). В отношении таких осужденных чаще всего применяется физическая сила (в 60 \% случаях). Физическая сила и специальные средства в совокупности применялись в 30 \% случаях, и только специальные средства в $10 \%$.

В большинстве случаев (80 \%) неправомерность применения в отношении осужденных физической силы и специальных средств проявлялась в превышении сотрудниками ИУ полномочий для подобного применения, направленного на пресечение совершаемых осужденными правонарушающих действий. В остальных случаях (20 \%) подобное применение без каких-либо поводов для этого. Неправомерное применение в отношении осужденных физической силы в подавляющем большинстве случаев (89 \%) было осуществлено в целях пресечения неповиновения или противодействия законным требованиям сотрудника ИУ, в остальных случаях (11\%) это применение было направлено на пресечение нападения осужденных на персонал ИУ, осужденных и иных лиц, посещающих данные учреждения. Неправомерное применение в отношении осужден- ных специальных средств в равных долях было связано с отражением нападения осужденных на персонал ИУ, осужденных и иных лиц, а также физического сопротивления, оказываемого осужденными сотрудникам ИУ.

В половине случаев рассматриваемое применение в отношении осужденных физической силы и (или) специальных средств было осуществлено в жилой зоне ИУ, 30 \% - в едином помещении камерного типа (ЕПКТ), 20 \% - штрафном изоляторе. Чаще всего (60 \%) подобное применение было осуществлено в дневное время (с 11.00 до 18.00), то есть во время наибольшей активности осужденных и проведения максимально большого числа проводимых режимных мероприятия. В остальных 30 \% рассматриваемое применение было осуществлено в утреннее время (с 6.00 до 11.00) и в меньшем числе случаев в вечернее время (с 18.00 до 23.00).

Негативным является то обстоятельство, что в большинстве случаев (70 \%) до применения физической силы и (или) специальных средств к осужденным не были применены не силовые способы пресечения совершаемых ими деяний, в остальных 30 \% случаев эти способы были применены, однако они не обеспечили пресечение совершаемых ими деяний.

Кроме того так же в большинстве случаев (60\%) осужденные не были предупреждены о применении в их отношении физической силы и (или) специальных средств и им не было дано достаточно времени для прекращения своего деяния. Вместе с тем положительным является то обстоятельство, что в подавляющем большинстве случаев (90 \%) сотрудниками ИУ осужденным, в отношении которых было осуществлено рассматриваемое неправомерное применение, была оказана необходимая медицинская помощь.

5. Характеристика сотрудников ИУ, неправомерно применивших в отношении осужденных лишению свободы физическую силу и специальные средства

Обобщение характеристик сотрудников ИУ, неправомерно применивших в отношении осужденных исследуемые силовые методы воздействия, позволил сделать вывод, что ими являются только мужчины, находящиеся в зрелом возрасте, большую долю из которых составили лица в возрасте 3135 лет (46,7 \%), 36-40 лет (26,7 \%). По остальным возрастным группам эти сотрудники распределились следующим образом: 21-25 лет (13,4 \%), 26-30 лет (6,6 \%) и 41-45 лет (6,6 \%). 
Данные сотрудники проходили службу в УИС достаточно продолжительное время: 26,7 \% из них на момент совершения рассматриваемого неправомерного применения проработали в данной системе от 4 до 6 лет, столько же - от 13 до 15 лет, каждый пятый - от 10 до 12 лет.

Безопасность в местах лишения свободы обеспечивают сотрудник оперативно-режимных подразделений. Именно поэтому не случайным оказалось то обстоятельство, что большей частью сотрудников, работающих в отделах безопасности и оперативных отделов ( $60 \%$ и 13,4 \% соответственно), были неправомерно применены силовые методы воздействия в отношении осужденных.

Так же большая часть (60 \%) из них имело высшее юридическое образование, что является весьма странным, поскольку, как правило, лицам с таким образованием свойственен высокий уровень правосознания и правовой культуры. 26 \% таких сотрудников имело только среднее профессиональное образование. Остальные 14 \% имели высшее техническое образование. Высшее образование в образовательной организации, относящейся к ФСИН России, получило только 13,3 \% таких сотрудников. Каждый пятый получил высшее образование в образовательные организации, относящейся к МВД России.

2/3 данных сотрудников имели опыт семейных отношений и были разведены, каждый пятый - не состоял в таких отношениях, и только практически каждый десятый в браке, что является весьма негативным обстоятельством, на который необходимо обращать внимание, поскольку социальное одиночество в определенной степени снижает уровень личной ответственности индивида за совершенные поступки $[8,9]$.

Большая часть (42 \%) данных сотрудников за все время службы в УИС не имели дисциплинарных взысканий, а 36,8 \% имели только поощрения. Только 21,2 \% таких сотрудников были получены дисциплинарные взыскания. Это указывает на то, что в большинстве данные сотрудники стремились проявлять позитивную активность в исполнении своих должностных обязанностей и не нарушать установленные законом условия несения службы, в частности, связанные с применением силовых мер воздействия в отношении осужденных.

\footnotetext{
1 Закон РФ от 21 июля 1993 г. № 5473-І «Об учреждениях и органах, исполняющих уголовные наказания в виде лишения свободы» // Ведомости Съезда народных депутатов и
}

В УИС взято за правило неукоснительного соблюдения нормативного предписания о проведении проверок профессиональную пригодность сотрудников ИУ к действиям в ситуациях, связанных с применением физической силы и специальных средств ${ }^{1}$. На практике эти проверки проводятся систематически, из чего можно сделать вывод, что неправомерность подобного применения, вероятнее всего, связано с так называемым «человеческим фактором», имеющим психологическую составляющую.

Исследование психологических характеристик данных сотрудников показало, что для них в большинстве характерны положительные качества, чем отрицательные. Среди положительных пенитенциарные психологи указали способность к самообладанию, верность интересам службы, авторитет среди коллег и осужденных, умение сдерживать себя, коммуникабельность, стрессоустойчивость и способность к самоконтролю, адекватное восприятие окружающей действительности, способнолсть находить компромисс в конфликтных ситуациях.

6. Характеристика причин и условий неправомерного применения в отношении осужденных к лишению свободы физической силы и специальных средств

Уяснение причин преступного поведения помогает лучше всего понять природу противоправного поведения криминального характера, выработать наиболее эффективные меры по его профилактике [10, с. 345-346].

В целях выяснения причин неправомерного применения в отношении осужденных к лишению свободы физической силы и (или) специальных средств, выявлении наиболее значимых из них для выработки в дальнейшем наиболее оптимальных направлений по их профилактике, и мер по реализации этих направлений, сотрудникам, проходящих службу в ИУ, в которых имели место быть данные применения, было предложено указать эти причины. Анализ результатов ответивших сотрудников позволил сделать вывод, что наиболее вероятными причинами подобных случаев являются:

- несоблюдение осужденными УПОН в ИУ;

- злостное несоблюдение осужденными УПОН в ИУ;

- провокации сотрудников ИУ со стороны осужденных;

Верховного Совета Российской Федерации. 1993. № 33. Ст. 1316. (ред. от 27.12.2019). 
- невыполнение осужденными законных требований сотрудников УИС;

- неблагоприятный морально-психологический климат и криминогенность мест лишения свободы;

- низкий уровень нравственности у некоторых сотрудников ИУ;

- неразвитость у некоторой части сотрудников ИУ навыков самоконтроля, умения сдерживать себя в ситуациях экстремального характера;

- особенности трудовой деятельности сотрудников ИУ, для которой характерен достаточно напряженный, ненормированный рабочий день, практически постоянные «перегрузки» на работе, необходимость выполнения трудовых обязанностей в нерабочее время, что почти всегда вызывает комплекс негативно-агрессивных эмоций;

- несовершенство законодательной регламентации, необходимой конкретизации применения физической силы и специальных средств (например, при возникновении состояний крайней необходимости или необходимой обороны);

- не всегда соответствующий всем необходимым требованиям отбор профессиональных кадров, способствующий принятию на службу лиц, не соответствующих требованиям, которым должен соответствовать сотрудник уголовно-исполнительной системы, работающий с осужденными к лишению свободы [11];

- феномен профессионального «выгорания» сотрудников ИУ, вызываемый негативными условиями и монотонностью работы в местах лишения свободы [12];

- деформация ценностных ориентаций, правовой культуры и правосознания сотрудников ИУ [13].

7. Профилактика неправомерного применения в отношении осужденных лишению свободы физической силы и специальных средств

Профилактика рассматриваемого неправомерного применения должна быть основана на четком и объективном понимании причини и условий его осуществления, представлении о лицах, его допустивших, и жертвах (осужденных) подобного обращения.

Реализация данной профилактики должна быть основана на принципах законности, справедливости и гласности, в силу чего необходимо выработать такой подход к искоренению рассматриваемого

2 Распоряжение Правительства РФ от 14 октября 2010 № 1772-р «О Концепции развития уголовно-исполнительной системы Российской Федерации до 2020 года» // Со- негативного явления в отечественной пенитенциарной практике, согласно которому ни один случай неправомерного применения физической силы и специальных средств в отношении осужденных к лишению свободы не был скрыт, а лица, виновные в подобном применении должны быть привлечены к справедливой ответственности.

Вероятность этого может быть достигнута максимально возможной открытостью функционирования УИС для государства и общества, которая определяется как один из важных признаков данной системы Концепцией развития уголовно-исполнительной системы Российской Федерации до 2020 года ${ }^{2}$.

Эффективность реализации профилактики рассматриваемого неправомерного применения определяется, по нашему мнению, реализацией следующих мер:

- проведение работы по пресечению фактов сокрытия неправомерного применения сотрудниками ИУ силовых методов воздействия в отношении осужденных, совершенных неправомерно;

- выявление и детальное изучение всех причин и условий, обстоятельств неправомерного применения физической силы и специальных средств в отношении осужденных к лишению свободы, с выработкой мер по недопущению подобного применения в дальнейшем с учетом условий функционирования конкретного ИУ;

- повышение качества подготовки и переподготовки квалифицированных сотрудников для УИС, способных исполнять свои должностные обязанности на высокопрофессиональном уровне;

- проведение работы по оздоровлению и поддержанию позитивного морально-психологического климата в коллективе сотрудников ИУ [14];

- профилактика увлечения сотрудников ИУ деструктивными социальными практиками (нарушение закона и установленных правил поведения в обществе, употребления алкоголя, ведение аморального образа жизни и т. д.) [15, с. 37];

- развитие института наставничества, оказание помощи в решении возникающих семейных и бытовых проблем сотрудников ИУ;

- разработка мер по стимулированию выполнения сотрудниками ИУ своих должностных обязанностей на должном уровне и, вместе с тем, по повышению требовательности к результатам их труда;

брание законодательства Российской Федерации. 2010. № 43. Ст. 5544. (ред. от 23.09.2015). 
- повышение качества проведения внутрисистемных проверок деятельности сотрудников ИУ, связанной с применением физической силы и специальных средств, при этом рассмотрения возможностей межведомственного взаимодействия в этом вопросе [16, с. 97];

- целенаправленная работа с лицами, отбывающими лишение свободы, по убеждению их в целесообразности правильного, нормативно определенного стиля общения с сотрудниками ИУ, необходимости важности выполнения ими законных требований данных сотрудников, непозволительности нарушения требований установленного порядка и условий отбывания наказания.

\section{8. Выводы}

Неправомерное применение физической силы и (или) специальных средств было осуществлено в отношении осужденных, с достаточно негативными характеристиками, отличающимся высокой степенью криминальной зараженности, деструктивными морально-психологическими качествами, проявляющими отрицательное отношение к порядку и условиям отбывания наказания, не подчиняющимся законным требованиям сотрудников ИУ.

Обобщение личностных характеристик сотрудников ИУ, неправомерно применивших в отношении лиц, отбывающих лишение свободы, рассматриваемые силовые методы воздействия, указывает на то, что в большинстве такие сотрудники отличаются положительными качествами. Это мужчины зрелого возраста, имеющие достаточный опыт работы в учреждениях УИС, необходимые навыки профессиональной деятельности, обладающие достаточным уровнем образования для ведения законопослушного образа жизни, именно поэтому они стремятся руководствоваться нормативными предписаниями, регламентирующими профессиональную деятельность сотрудника УИС, и проявляют позитивную активность в выполнении своих должностных обязанностей. Для таких сотрудников характерны положительные психологические качества, в целом соответствующие профессиональной пригодности.

Наиболее вероятные причины неправомерного применения силовых методов воздействия в отношении осужденных связаны с характером противоправной активности и различного рода провокациями с их стороны, а также с негативными особенностями несения службы, обусловленными спецификой мест лишения свободы.

Изложенные в работе меры по профилактике рассматриваемого негативного явления в отечественной пенитенциарной практике могут оказать позитивное воздействие на повышение уровня функционирования УИС, соответствующего нормативным предписаниям национального и международного уровня.

\section{СПИСОК ЛИТЕРАТУРЫ}

1. Shandra B.B. The change of person's worldview in the process of the criminal world subculture formation / B.B. Shandra, I.Y. Ostapets // Sciences of Europe. - 2019. - Vol. 36, № 3. - Pp. 64-68.

2. Tygart C.E. Criminal subculture influence among middle-class and nonaffluent youth / C.E. Tygart // Urban Education. - 1981. - Vol. 15, № 4. - PP. 481-484.

3. Richards S.C. USP Marion. The first federal supermax / S.C. Richards // The Prison Journal. - 2008. - Vol. 88, № 1. - Рp. 6-22.

4. Смирнов А.М. Длительные сроки лишения свободы в отношении осужденных мужчин (уголовно-правовые и уголовно-исполнительные аспекты): дис. ... канд. юрид. наук / А.М. Смирнов. - Вологда, 2009. - 247 с.

5. Echeburúa E. Psychopathological profile of men convicted of gender violence. A study in the prisons of Spain / E. Echeburúa, Ja. Fernández-Montalvo, P.J. Amor // Journal of Interpersonal Violence. - 2003. - Vol. 18, № 7. Pp. 798-812.

6. Спасенников Б.А. Природа половых эксцессов осужденных и основные направления их профилактики в условиях исправительных учреждений нового вида / Б.А. Спасенников, А.М. Смирнов // Уголовно-исполнительное право. - 2011. - № 2. - С. 33-36.

7. Кириллов М.А. Частная жизнь осужденных к лишению свободы как объект правового регулирования / М.А. Кириллов, А.Л. Санташов, М.А. Ступалова // Уголовно-исполнительное право. - 2014. - № 11. - С. 24-28.

8. Johnson H.D. Peer conflict avoidance: associations with loneliness, social anxiety, and social avoidance / H.D. Johnson, J.C. LaVoie, M.C. Spenceri // Psychological Reports. - 2001. - Vol. 88, № 1. - Pp. 227-235.

9. Каштанова О.В. Контексты социального одиночества и социальный конфликт / О.В. Каштанова. - Казань: Казанский национальный исследовательский технологический университет, 2015. - 132 с. 
10. Криминология / под общ. ред. А.И. Долговой. - 3-е изд., перераб. и доп. - М.: НОРМА, 2007. - 912 с.

11. Бубнова Ю.Г. Проблемы формирования профессиональной мотивации будущих сотрудников уголовно-исполнительной системы / Ю.Г. Бубнова // Уголовно-исполнительная система: право, экономика, управление. - 2014. - № 1. - С. 24-26.

12. Maslach C. Maslach Burnout Inventory manual / C. Maslach, S.E. Jackson. - Palo Alto: Consulting Psychologists Press, 1986. - P. 83-87.

13. Смирнов А.М. Феномен правового нигилизма в российском обществе и готовность граждан к внесудебным способам разрешения криминальных конфликтов / А.М. Смирнов // Пробелы в российском законодательстве. - 2014. - № 3. - С. 143-146.

14. Вилкова А.В. Психология и педагогика в профессиональной деятельности воспитателя / А.В. Вилкова, Н.П. Гнедова // Уголовно-исполнительная система: право, экономика, управление. - 2014. - № 3. - С. 12-16.

15. Трофимова Е.Л. Профессиональные трансформации сотрудников пенитенциарных учреждений / Е.Л. Трофимова // Психология в экономике и управлении. - 2016. - Т. 8, № 1-2. - С. 36-42.

16. Потапов А.М. Социальный контроль за лицами, отбывшими наказание в виде лишения свободы / А.М. Потапов, А.Л. Санташов // Вестник института: преступление, наказание, исправление. - 2012. - № 2. C. 94-98.

\section{REFERENCES}

1. Shandra B.B., Ostapets I.Yu. Changing the worldview of a person in the process of forming a subculture of the criminal world. Science of Europe, 2019, no. 36-3, pp. 64-68.

2. Tigart K.E. The influence of criminal subculture among representatives of the middle class and wealthy youth. Urban education. 1981, vol. 15, no. 4, pp. 481-484.

3. Richards S.S. USP Marion. The first federal supermax. The Prison Journal, 2008, vol. 88, no. 1, pp. 6-22.

4. Smirnov A.M. Criminal law and penal aspects. Cand. Diss. Vologda, 2009. 247 p. (In Russ.).

5. Echeburúa E., Fernández-Montalvo Ja., Amor P.J. Psychopathological profile of men convicted of genderbased violence. A study in prisons in Spain. Journal of interpersonal violence, 2003, vol. 18, no. 7, pp. 798-812.

6. Spasennikov B.A., Smirnov A.M. Sexual excesses of convicts and the main directions of their protection in conditions of correctional institutions of a new kind. Ugolovno-ispolnitel'noye parvo = Penal law, 2011, no. 2, pp. 33-36. (In Russ.).

7. Kirillov M.A., Santashov A.L., Stupalova M.A. The personal life of prisoners as an object of legal regulation. Ugolovno-ispolnitel'noye pravo= Penal law, 2014, no. 11, pp. 24-28. (In Russ.).

8. Johnson H.D., LaVoy J.S., Spencery M.S. Conflict avoidance with peers: associations with loneliness, social anxiety and social avoidance. Psychological reports, 2001, vol. 88, no. 1, pp. 227-235.

9. Kashtanova O.V. Contexts of social loneliness and social conflict. Kazan, Kazan National Research Technological University, 2015. 132 p. (In Russ.).

10. Dolgova A.I. (ed.). Criminology. Moscow, NORMA Publ., 2007. 912 p. (In Russ.).

11. Bubnova Yu.G. Problems of forming professional motivation of future employees of the penal system. Ugolovno-ispolnitel'naya sistema = Criminal-Executory System: law, economy, management, 2014, no. 1, pp. 24-26. (In Russ.).

12. Maslach S., Jackson S.E. Maslach Burnout Inventory manual. Palo Alto: Consulting Psychologists Press, 1986. Pp. 83-87.

13. Smirnov A.M. The phenomenon of legal nihilism in Russian society and citizens ' readiness for non-judicial ways to resolve criminal conflicts. Probely v rossiyskom zakonodatel'stve = Gaps in Russian law, 2014, no. 3, pp. 143146. (In Russ.).

14. Vilkova A.V., Gnedova N.P. Psychology and pedagogy in the professional activity of the teacher. Ugolovnoispolnitel'naya sistema = Criminal-Executory System: law, economy, management, 2014, no. 3, pp. 12-16. (In Russ.).

15. Trofimova E.L. Professional transformations of prison staff. Psikhologiya $v$ ekonomike $i$ upravlenii $=$ Psychology in Economics and Management, 2016, vol. 8, no. 1-2, pp. 36-42. (In Russ.).

16. Potapov A.M., Santashov A.L. Social control over persons serving a sentence of imprisonment. Vestnik instituta: prestupleniye, nakazaniye, ispravleniye = Institute Bulletin: Crime, Punishment, Correction, 2012, no. 2, pp. 94-98. (In Russ.). 


\section{ИНФОРМАЦИЯ ОБ АВТОРЕ}

Смирнов Александр Михайлович - доктор юридических наук, доцент, главный научный сотрудник НИЦ-2

Научно-исследовательский институт ФСИН России 125212, Россия, г. Москва, ул. Нарвская, 15а/1

E-mail: samnauka@mail.ru

SPIN-код РИНЦ: 1481-6590

ORCID: 0000-0003-4779-4971

ResearcherID: M-8979-2018

\section{БИБЛИОГРАФИЧЕСКОЕ ОПИСАНИЕ СТАТЬИ}

Смирнов А.М. Неправомерное применение в отношении лиц, лишенных свободы, физической силы и специальных средств: криминологическая характеристика и меры профилактики /

А.М. Смирнов // Правоприменение. - 2020. - Т. 4, № 3. - C. 148-157. - DOI: 10.24147/2542-1514.

2020.4(3).148-157.

\section{INFORMATION ABOUT AUTHOR}

Alexander M. Smirnov - Doctor of Law, Associate Professor, Chief Researcher, Research Center-2 Research Institute of the Federal Penitentiary Service of Russia

15a/1, Narvskaya ul., Moscow, 125212, Russia

E-mail: samnauka@mail.ru

RSCI SPIN code: 1481-6590

ORCID: 0000-0003-4779-4971

ResearcherID: M-8979-2018

\section{BIBLIOGRAPHIC DESCRIPTION}

Smirnov A.M. Illegal use of physical force and special means against prisoners: criminological characteristics and preventive measures. Pravoprimenenie $=$ Law Enforcement Review, 2020, vol. 4, no. 3, pp. 148-157. DOI: 10.24147/2542-1514.2020.4(3). 148-157. (In Russ.). 